\title{
USING INTERNSHIPS TO ENGAGE SOCIAL SCIENCE STUDENTS IN THE PRACTICE AND DEVELOPMENT OF DATA SKILLS
}

\author{
Mark Brown and Jackie Carter \\ The School of Social Sciences, University of Manchester \\ Mark.brown@manchester.ac.uk
}

There is growing recognition that good (quantitative) data skills are an essential part of a graduates skill set in an increasingly competitive jobs market. This is the context for the UK's ' $Q$ Step' programme, a strategic response to a widely reported shortage of these skills among social science graduates. This paper describes an initiative at the University of Manchester Q-Step Centre to pilot the use of internships as an integral part of quantitative training in the undergraduate curriculum, enabling students to apply and practice the skills they have learned in the classroom in a workplace setting. The internships involve students being placed on data led research projects with a diverse range of employers for eight weeks over the Summer. Now in the fourth year of the programme our evaluation is highlighting the potential of internships to help motivate and build confidence in the use of quantitative skills, with a number of interns going on to undertake data led dissertations and specialize further at postgraduate level.

\section{INTRODUCTION}

Employability is writ large in today's higher education landscape, with employers increasingly seeking evidence of graduates' ability to understand, analyse and be critical of statistics. A deficit of these skills nationally (and particularly in the Humanities) has been highlighted in a series of high profile strategy reports from Research Councils, Government and Industry (ESRC, 1987; HEFCE, 2005; Mills, Jepson, Coxon, Easterby-Smith, Hawkins, \& Spencer, 2006; MacInnes, 2009). This is the context for Q-Step, a national initiative funded by the Nuffield Foundation, the Economic and Social Research Council (ESRC) and HEFCE to promote a stepchange in quantitative social science training. Under this initiative fifteen universities were given five-year funding from 2013 to develop innovative and experimental approaches to deliver on this objective. The Manchester Q-Step Centre (www.manchester.ac.uk/q-step) has been focusing on the student learning experiences both inside and outside the classroom. Alongside a major programme of new and re-designed courses (and some specialist degree pathways) a key feature of the Manchester approach, and the focus of this paper, has been investment in a programme of work internships. These have been designed to integrate with learning on the taught programme, providing a clear connection between the skills taught in the classroom and their application in the workplace. The collective aim is to present data skills as an integral part of a social science degree, and to demonstrate their relevance in the graduate jobs market.

\section{THE INTERNSHIP PROGRAMME}

\section{The Pedagogic Rationale}

There is growing recognition that students learn data skills best through practice and application (Buckley et al, 2015). Too often in the past quantitative methods have been taught in the social sciences as a set of technical skills, detached from their applications and lacking integration with rest of the curriculum (Neumann, Hood, \& Neumann, 2013). In recent decades great strides have been made to contextualize this training with the greater use of real world data and an embedding within substantive applications, an approach emphasized in the influential Guidelines for Assessment and Instruction in Statistics Education (GAISE) (Carver et al., 2016). This has been the approach at Manchester where all our quantitative training has a strong emphasis on hands on training in labs using relevant data to address real and pertinent social research questions that map on to our students subject interests. It is an approach that has helped overcome some of the traditional hostility to the 'stats class', evidenced in improved student evaluation scores and more students taking follow up quantitative options (Buckley et al, 2015). Using real data to answer real questions within a framework of problem based learning has helped make the modern statistics class a more relevant and engaging experience, particularly for social science students 
where anxiety over mathematics and number are widely reported barriers to learning. It is an approach where the integration of work based learning through short intensive research led internships offers many potential benefits (Curtis and Blair, 2010).

First, work-based learning can provide the most authentic experience of how quantitative skills are applied to solve real problems. Students encounter data in the way it normally appears in the real world, messy and incomplete, contrasting with the sanitized teaching datasets frequently used in a taught class. It is an environment within which 'learning statistics' is about learning which techniques are suitable to apply given a particular problem and data set, rather than a mechanical 'how to' learning of techniques in a statistics curriculum. Perhaps most crucially in contrast to course based teaching of statistics where the constraints of timetabling mean classes are typically taught in weekly sessions of a couple of hours at most, work-place learning provides a more immersive learning experience with much greater opportunity to develop the confidence in working with data and statistics that comes through daily familiarity, practice and repetition.

\section{The Design of the Programme}

The Manchester Q-Step internship programme involves the placement of students with an organization for around 8 weeks full time, over July and August, at the end of their second year of study. To be eligible students are required to have undertaken one of a list of 'quantitative' course options in their second year, and selection is a competitive process involving a written application and interview. We support around 50 placements annually. The host organizations are highly diverse, ranging from national and local Government, service providers, media companies, think tanks and local charities (see www.manchester.ac.uk/q-step/internships/). However the common denominator in all of them is a research led project involving the practice and development of quantitative skills applied to social data. This may include elements of primary data collection (a number of our interns have been in involved in the design and implementation of surveys) of desktop research involving the sourcing and evaluation of secondary sources, through to more technical projects focused on the statistical analysis of a dataset. This diversity of projects and employer (covering many of the more popular career paths among social science undergraduates) sends the powerful message to students that quantitative data skills are not the exclusive preserve of statisticians and data analysts but that a confidence to use and make sense of data (a statistical literacy) is a common requirement in almost any graduate career.

A significant part of the set-up process has been the need to manage employer expectations. The context for our internships is made clear (to support the practice and development of student data skills rather than a resource to increase research capacity) as is the requirement for a close support and mentoring of the intern within the organization (interns are also given a mentor at the University). In designing suitable projects, employers are informed about the level of quantitative training typically received by our students, though this varies considerably between eligible degree programmes. Project briefs are advertised on-line in the spring term, with each specifying the essential and desirable skills required for that particular internship. This has the specific purpose of guiding students in the selection of suitable placements (they can apply for up to three). It also serves to make more explicit to students (and to teaching staff) the set of quantitative skills that are routinely expected by the majority of graduate employers (for example almost all of our host organisations expect students to have a good command of Excel)

It is recognized that the transition from class-based tuition to workplace learning is a demanding one and a key part of the recruitment process is a pre-placement workshop attended by all interns. This is used to address practical aspects of an internship, from managing HR requirements to the importance of adapting to organizational work cultures (including punctuality and dress codes). It also provides an opportunity to provide some additional more bespoke quantitative training. Informed by completion of a personal skills audit and the specific requirements of their placement, students choose from a selection of intensive computer workshops covering basic and more advanced training in statistics (from exploratory analysis to regression modeling) and software (basic and advanced Excel, GIS and R).

Currently our internships are not formally assessed as part of the degree. This is in part dictated by the fact that the Summer vacation represents the only opportunity in the undergraduate calendar to locate a full-time eight week internship, which we, in consultation with our host 
organisations, consider the minimum time required to undertake this type of project-based placement. This puts it outside the scope of the annual June Exam Boards and thus rules out any credit bearing contribution to the students degree. However all interns are required to provide two pieces of reflective writing on their experiences (mid-way through and at the end of their placement) and to produce a poster of their work. The poster presentation (alongside selected oral presentations) provides the main component of a student conference event in the Autumn. This brings together interns, employers, key invites from University management and the wider Higher Education sector, and the next cohort of Q-step students (those currently in year 1) in a celebration of the interns work. A panel of discussants provides reflections on each presentation and awards prizes (for both oral presentation and posters).

\section{OUTCOMES}

While the benefits of workplace learning are well documented (Curtis and Blair, 2010; Carter, Brown and Simpson, forthcoming) we are less aware of other initiatives embedding social science undergraduates into workplace settings to specifically apply and develop their statistical and data skills. In that context we are keen to provide systematic evaluation of the Manchester model.

To help build an evidence base we are collecting a range of data from both student and employer perspectives prior, during and after placement. This includes the student reflective writing pieces mentioned earlier, short surveys, and in-depth interviews with both students and employers. This work is written up elsewhere (Carter Brown and Simpson, forthcoming) and is also the basis for videos and case-studies (see the 'student stories' section of www.manchester.ac.uk/q-step). From the work we have already done it is clear that the opportunity to practice and apply skills in real world research settings has provided a transformative experience for many of our students, building their confidence in the use of number and in some cases inspiring them to rethink career paths. This is reflected in the progression of a number of Q-Step interns to take specialist quantitative course options and dissertations (some using data from their internships) in their final year, with some even progressing to postgraduate level training (six so far have taken our MSc in Social Research Methods and Statistics (SRMS) a specialist programme providing advanced research training in quantitative method. These students have identified their internship experience as both a motivator and an enabler for these decisions. This is discussed more fully elsewhere using detailed cases studies (Carter, Brown and Simpson forthcoming).

While evaluation is ongoing we can already identify some distinct features of the internship experience that are contributing to the Q-Step goals of raising statistical literacy among undergraduates in the social sciences and inspiring the next generation of quantitative specialists.

One unexpected feature concerns the extent to which they have facilitated the learning of new skills. The primary rational for the internships had been to make a direct connection between the learning of quantitative skills in the classroom and their application in the workplace. We had anticipated that the real-world context would help motivate and enthuse students to engage with quantitative data, and that the opportunity to practice and apply skills would build confidence and understanding in the techniques and concepts they had learned on their courses. However, we had not appreciated the extent to which they would provide the conditions for 'new' learning. Many interns have returned from the Summer with a considerably enhanced set of data skills. This includes confidence in handling and cleaning data, as well as the ability to apply and understand more advanced techniques of analysis (students starting placements with no more than a basic training in descriptive statistics have returned eight weeks later able to design and interpret multiple regression models). In many cases this has extended to learning completely new software packages. This represents an impressive learning curve when set against the more modest progression observed in a typical (11 week) taught methods course, and raises salient questions about pedagogy and learning style. From our evaluation data it is clear that the students enthusiasm for the research questions, the intensive day to day emersion in the project, and the support offered from being embedded into a research team, were all contributory factors, but we are keen to do more research on this question.

Another feature of the internships has been their effectiveness in engaging students without strong prior experience or interest in statistics. The three cohorts to have completed internships 
have been drawn from a highly diverse range of degree programmes, and includes students who through their own admission had lacked confidence or interest in quantitative work. While awarded through a competitive recruitment process, the eligibility criteria for applying have avoided overly prescriptive requirements in terms of grades or quantitative experience, and in marketing the internships we have emphasized the substantive applications rather than the statistics. Given the high levels of statistics anxiety among our target students (Buckley et al 2015) this was a necessary strategy to avoid the internships ending up appealing only to a niche community of students already predisposed to quantitative methods. In practice it has been the demonstration that application led internships can be highly effective in engaging and inspiring the quants-wary student that has been one of the most important findings of our pilot, particularly in the context of the wider goals of QStep to extend statistical literacy to students on mainstream social science programmes.

A third observation is that internships can be a catalyst for further specialism. For almost all our interns the experience has served to help dissipate the fear and anxiety around statistics and working with quantitative data. But for many their involvement in these intensive research focused projects have also inspired them to seek further quantitative training (and in some cases to rethink career paths). The emergence of 'q-step' students as a new source of recruitment for our specialist MSc Social Research Methods and Statistics is a stand out development.

\section{CONCLUSION}

The Manchester Q-Step internship programme provides a model for the embedding of workbased learning into the practice of quantitative methods teaching in the UK HE. Early evaluation has highlighted a number of positive impacts on the student learning experience, including the motivational aspects of real world applications and the advantages of sustained practice and intensive engagement on a data problem as a way of building understanding and confidence in the handling and interpretation of numeric data and statistics. Entering the fourth round of recruitment our programme continues to grow and gain popularity among students and employers, with the inclusion of new organisations and a steady increase in the number of student applications. The numbers of interns motivated to take further quantitative training, including postgraduate specialization is particularly encouraging. However, as we approach the end of the funding period (in 2019) we can identify a number of challenges.

The major challenge is how to incorporate the internship experience within a more sustainable funding model. The payment of a living wage to all interns and the high support and administration costs make our internships expensive and heavily dependent on external project funding. Alignment with strategic priorities of the University around employability have led to matched funding, allowing us to expand the number of placements offered, though the 50 internships we currently offer is already being outstripped by student demand. Continuation of the current model beyond the life of the project will almost certainly require a move to some cofunding with employers. An alternative approach would be to make the internships a credit bearing component of the core degree curriculum. This would present challenges of how to assess and require some scaling down of the current format ( 8 week full-time) to accommodate it alongside the rest of the curriculum. The benefits would be an opportunity to extend the value of work-based learning to all students on the degree programme.

Alongside the challenges of developing a sustainable model for internships, we are keen to conduct further evaluation research related to curriculum innovation and the pedagogic aspects of work based learning. Evaluation of internships to date (at Manchester and more generally in the literature) has largely concerned their effectiveness in helping prepare students in the transition to employment. However, the Q-Step internship programme also provides a unique opportunity to 'reflect back' and ask some searching questions about our classroom teaching of quantitative methods and statistics. It is a question not only about curriculum content but of pedagogic approach. The fact that our students have had such positive quantitative learning experiences on placement invites critical reflection on the pedagogy used in the methods class, where many students continue to be anxious and unmotivated when confronted with 'learning statistics'. The internship model we have developed at Manchester remains experimental but the early evaluation we have done demonstrates the exciting potential of work based learning to motivate and enable students to become more confident users of data and statistics. More research is required into 
optimal models for integrating it within the taught curriculum but it surely has an important part to play in an evolving response to the quantitative skills agenda and meeting the goal of statistical literacy for all.

\section{REFERENCES}

Buckley, J., Brown, M., Thomson, S., Olsen, W., \& Carter, J. (2015). Embedding quantitative skills into the social science curriculum: Case studies from Manchester. International Journal of Social Research Methodology, 18(5), 495-510.

Carter, J., Brown, M., and Simpson, K. (forthcoming) From the classroom to the workplace: how social science students are learning to do data analysis for real. Special Edition of Statistics Education Research Journal

Carver, R., Everson, M., Gabrosek, J, Horton, N., Lock, R., Mocko, M., Rossman, A., Rowell, G. H., Velleman, P., Witmer, J., Wood, B. (2016). Guidelines for assessment and instruction in statistics education (GAISE) college report 2016. Alexandria, VA: American Statistical Association. [Online: www.amstat.org/education/gaise]

Curtis, S. \& Blair, A. (Eds.) (2010). The scholarship of engagement for politics: placement learning, citizenship and employability. Birmingham: The Higher Education Academy Network. [Online: papers.ssrn.com/sol3/papers.cfm?abstract_id=2085623]

ESRC (1987). Horizons and opportunities in the social sciences. London: Economic and Social Science Research Council.

HEFCE (2005). Strategically important and vulnerable subjects: Final report of the advisory group. Higher Education Funding Council for England. [Online: image.guardian.co.uk/sysfiles/Education/documents/2005/06/28/shortage.pdf]

MacInnes J. (2009). Proposals to support and improve the teaching of quantitative research methods at undergraduate level in the UK. London: Economic and Social Research Council (ESRC).

Mills, D., Jepson, A., Coxon, T., Easterby-Smith, M., Hawkins, P., \& Spencer, J. (2006). Demographic review of the UK social sciences. London: Economic and Social Research Council (ESRC). [Online: core.ac.uk/download/pdf/278774.pdf]

Neumann, D. L., Hood, M., \& Neumann, M. M. (2013). Using real-life data when teaching statistics: Student perceptions of this strategy in an introductory statistics course. Statistics Education Research Journal, 12(2), 59-70. [Online: iaseweb.org/Publications.php?p=SERJ_issues]

Nuffield Foundation (2013). Universities awarded $£ 19.5$ million for overhaul of quantitative social science training. A step-change in quantitative social science skills. [Online: www.nuffieldfoundation.org/news/universities-awarded-\%C2\%A3195-million-overhaulquantitative-social-science-training] 